\title{
Ethical and Policy Issues in Genetic Prediction of Violence: Implications for Clinicians
}

\author{
David Wasserman
}

Published online: 23 August 2014

(C) Springer Science + Business Media New York 2014

\begin{abstract}
This paper reviews the ethical and policy issues raised by current biomedical research into violent behavior. Increasing awareness of the environmental mediation of genetic influence may not reduce the risks of social control and stigmatization. The review concludes that (1) public anxiety about mass killings and mental illness will increase pressure to detect individual biological features that predispose to crime. The pressure to find such individual differences may be even greater than it was in the 1990s, when more pervasive violent crime was easier to attribute to "shared environment." Further, it concludes (2) that the recognition of early environmental factors in predispositions to violent crime may increase pressures on parents to ensure the good behavior of their children; and (3) that these first two developments will sharpen role conflicts for clinicians expected to serve as both protectors of their patients' health and protectors of public safety.
\end{abstract}

Keywords Genetic predispositions · Violence ·

Prediction · Early intervention - Parental autonomy .

Professional conflicts

\section{Introduction}

Two decades ago, the claim that biological markers would be found for predispositions to antisocial and violent behavior was greeted with both skepticism and concern. The skepticism arose from doubts that genes shaped complex social behaviors in ways that could meaningfully contribute to the assessment of individual risk. The concern

D. Wasserman ( $\square)$

4324 Woodberry Street, University Park, MD 20782, USA

e-mail: dtwasserm@gmail.com arose from fear that whether or not genes could actually contribute in these ways, they would be believed to do so by policymakers, law enforcement, and the public, raising serious threats of coercion and stigmatization. The debate about the prospects for finding predictive markers, and about their value and risks, reached a fever pitch at a time when violent crime in the United States was at record highs. Proponents of biological research into crime saw an urgent need for enhanced prediction; critics saw an enormous potential for abuse [1].

Two decades later, there have been modest but credible findings of genetic variants associated with an increased risk of antisocial and violent behavior in the presence of sustained environmental "stressors" [2]. The potential for genetically based prediction is limited by the small role that any one gene plays in accounting for or contributing to complex behavior. According to a recent review article by two leading proponents of biomedical approaches, no gene has been found that predicts aggression at a $1 \%$ level of significance, and no gene has been found that accounts for more than $1 \%$ of the variance for any complex behavioral trait [3]. The greater predictive potential lies in neurological features to which genes contribute, but which can be more directly assessed. Genetic testing, however, will continue to have considerable importance in identifying variants that significantly predict antisocial behavior in interaction with environmental factors.

During the same period that saw the identification of genetic and neurological features which appear to interact with environmental factors to increase the risk of violence $[2,3]$, the overall rate of violent crime declined in the United States to 50-year lows, and violent crime is, in general, no longer perceived as a top national problem [4]. At the same time, in response to a number of highly 
publicized killing sprees over the past 15 years, there has been a sharp increase in public anxiety about mentally ill, violence-prone individuals. This anxiety has led to a high level of public demand and public funding for research into biological causes of crime [5].

This review of ethical and policy issues raised by current biomedical research into violent behavior takes close account of this changing social landscape, and emphasizes that increasing recognition of the environmental mediation of genetic influence may not have a benign impact on social practice and policy. The dangers of social control and stigmatization will remain even if there is less risk of seeing individuals as "born bad," and even if there is increased use of environmental interventions in place of, or in addition to, biomedical interventions. Specifically, I will argue (1) that the public's anxiety about mass killings and mental illness will increase pressure to detect individual biological or psychological features that predispose to crime. The pressure to find such individual differences may be even greater than it was in the 1990s, when more pervasive violent crime was easier to attribute to "shared environment." I will also argue (2) that the recognition of early environmental factors in predispositions to violent crime may place more pressure on childbearing women, especially poor ones, to ensure the good behavior as well as the good health of their children, and (3) that these first two developments will create or sharpen role conflicts for clinical practitioners in obstetrics/gynecology and pediatrics, expected both to protect their patients' health and to protect public safety.

These concerns reflect the more general concerns about appropriate use of biomarkers raised by human genome research, with the public and policy makers likely to continue to overestimate the predictive potential of single makers, to underestimate the importance and complexity of bio-social interactions, and to subject "predisposed" individuals to coercive or stigmatizing treatment. Even when the critical role of environmental factors is recognized, the availability of psychotropic drugs may make biological contributions appear more tractable.

Increased sophistication of biomarker research, and growing appreciation of bio-social interactions, will not necessarily eliminate or reduce these concerns. Moreover, reducing some concerns may introduce or sharpen others. Thus, to the extent that predispositions to violence are not seen as immutable, they are likely to be seen as most mutable in early childhood. Some early interventions for some conditions may be highly effective. But a focus on early intervention to prevent violence would carry serious risks: prematurely medicating children with powerful psychotropic drugs; separating children identified as predisposed from their "normal" peers, to the social and educational detriment of both; and infringing the autonomy of parents with demands that they avoid a variety of environmental and social "risk factors" and make special protective provisions for their predisposed children.

\section{The Shifting Focus: From "Urban Jungles" to Suburban High Schools}

The first U.S. Government proposal to explore the biological basis of crime, the so-called "violence initiative," was sponsored by the administration of George H.W. Bush. According to its architect, Frederick Goodwin, it was intended to identify "individual vulnerabilities" to violent and antisocial behavior and develop preventative interventions. Ironically, what doomed the proposed initiative was the public furor over remarks Goodwin made that emphasized environmentally based vulnerabilities. He suggested that deteriorating social conditions in poor inner-city neighborhoods brought out aggressive behavior on the part of their young male residents. Drawing an unfortunate, and seemingly racially charged, analogy to the behavior of rhesus monkeys in adverse conditions, he suggested that the term "urban jungle" might be understood literally rather than figuratively. Of most enduring significance was Goodwin's implicit view that individual vulnerabilities were being revealed in the crucible of innercity life [6].

Although the federal government dropped the violence initiative, it continued to fund research on biological factors in violent and antisocial behavior [6]. The next major upsurge in federal interest came in response to a very different kind of violence than the inner-city crime that worried Goodwin: the April, 1999 Columbine High School massacre in which two white students from a middle-class, suburban high school engaged in a "methodical murder spree, killing 12 of their peers, a teacher, and themselves" [6]. Subsequent investigation revealed the tortured thoughts, emotions, and lethal fantasies of the two killers. "Researchers, however, had few immediate answers to offer a public desperate to know what demons were tormenting middle-class white children in the suburbs" [6]. Unencumbered by the suspicion of racial bias, President Clinton, Surgeon General David Satcher, and NIMH Director Steven Hyman created research and intervention programs that treated youth violence as a disease and public health problem. Although the primary emphasis of these initiatives was on social and environmental factors, the treatment of violence as a disease suggested a significant biological contribution. NIMH in particular maintained a strong interest in genetic and other biological factors [6].

Since Columbine, there have been at least a dozen highly publicized spree killings at US schools, military 
facilities, movie theaters, and shopping malls. Despite the dramatically declining rate of violent crime overall, these incidents are especially frightening to the public, because of the fear that they could happen anywhere to anyone. Unlike the increased violent crime of the 1990s, seen to result from a "shared environment" in which authority figures and role models vanished while crack proliferated [7], the isolated killing sprees of the past 15 years appear to result from individual pathology, albeit exacerbated by violent video games, internet inspiration and guidance, and the easy availability of deadly weapons [8]. Because most of these killings have been committed by young middleclass white males, public pressure to detect and constrain risky individuals does not appear to be tainted by the racial stereotypes that loomed large in the 1990s. But current public pressure to detect and constrain predisposed individuals threatens the hard-won rights of those diagnosed with psychiatric disorders [9]. Further, this preventative emphasis may encourage a disturbing conflation of health care and child welfare functions on the one hand, and public safety and law enforcement functions on the other [10].

The use of biomarkers in preventing violence is relatively less problematic for individuals who have already been convicted of violent offenses. It might be argued that such biological evidence could only improve the judgments of future dangerousness already made by mental health professionals at sentencing and parole hearings. On the other hand, such biological evidence might give the appearance of precision to predictions now viewed with a healthy degree of skepticism. And even in these contexts, involuntary testing would raise search and seizure issues. Giordano et al. [9] note that the US Supreme Court has already permitted nonconsensual blood draws to provide direct evidence of a crime (driving while intoxicated) and for future criminal identification. Arguably, it would be a greater intrusion to use a blood draw to predict future dangerousness. It would be even more troublesome to impose such testing on individuals involuntarily committed for posing a threat to themselves or others, who had not been arrested or convicted of a violent offense, or to test individuals who merely had a history of criminal behavior or mental illness, a current diagnosis of psychiatric disorder, or a record of "deviant" but unthreatening speech or behavior [11]. In all of these cases, the individual should enjoy the same civil liberties as any other citizen [9]. Even if there is predictive value in a history of violent or deviant behavior, there is insufficient justification to override such an individual's civil rights to perform nonconsensual biological testing to quantify or render "more scientific" such prediction.

\section{Early Detection and Prevention: Potential Challenges to Parental Autonomy and Family Privacy}

The psychiatric profession has now rejected simplistic explanations of mental disorder based on deficient nurturing, such as the notorious hypothesis that autism was caused by cold, unresponsive mothers [11]. But current research may increase the potential for holding parents, particularly mothers, partly responsible for the violent behavior of their children. The public already seems eager to blame parents, as illustrated by the outcry over reports that the mother of the Newtown killer, Adam Lanza, had often taken him shooting at rifle ranges [12]. Biomedical research is likely to emphasize parental contributions at earlier stages of development, and to expose sins of omission as well as commission.

Consider a description of some early childhood environmental factors found to increase the risk of violence in later years:

The seeds of sin are sown early in life-and not just by genes. Toxic early environments also worsen brain functioning. Mothers who smoke or drink during pregnancy double or triple the odds of their babies becoming violent offenders decades later, even after accounting for other social influences. Birth complications also predispose to adult violence, especially when combined with negative home environments. Poor nutrition during pregnancy almost triples the rate of antisocial personality disorder in adulthood. Children with poor nutrition at age 3 are more aggressive and antisocial in the teenage years after controlling for a host of social adversity factors. All of these early influences impair brain structure and function, and they contribute to the brain impairments we find in criminal and psychopaths in later life [13].

This description comes from Adrian Raine, a leading bio-psychologist of violence, in a CNN opinion piece. His list yields implicit social prescriptions for reducing future criminality. Some, like good nutrition, are fairly easy for middle-class parents to satisfy. Others, like forgoing smoking and drinking during pregnancy, may be very difficult for some women regardless of social or economic status. Still others, like avoiding birth complications and negative home environments, may be beyond the control of the most conscientious parents.

Yet Raine argues that some fairly unintrusive interventions have yielded striking reductions in criminality:

Providing nurse visitation to poor mothers where advice is given on reducing smoking and alcohol use cuts juvenile delinquency in half 15 years later. Early environmental enrichments that include better 
nutrition, more exercise, and cognitive stimulation from ages 3 to 5 both improve brain functioning at age 11 and also reduce crime at age 23 by $35 \%$ [13].

According to Raine, successful interventions are not limited to small children. Supplementing the diet of young prison inmates with Omega-3 also reduces serious offending by $35 \%$. Raine ends his piece on a note at once optimistic and defensive:

If we were to promote a minimal biological baseline for the healthy brain development of every child in society to reduce the likelihood of future violence of the kind we saw at Sandy Hook, is that really eugenics? No it is not [13].

The danger, however, is not eugenics, but oppressive social control over child-rearing. Some of the measures that Raine touts, taken by themselves, appear to be free of that danger. It is hard to see anything wrong with attempting to ensure adequate nutrition, exercise, and cognitive stimulation for preschool children, or adding a generally healthy supplement to prison diets. These measures are not stigmatizing because they are population-wide rather than predisposition-specific. Every 3-5-year-old child would get preschool enrichment; all young offenders would get the improved diet. But achieving a "minimal biological baseline for the healthy brain development of every child in society" would require far more than such population-wide measures. Raine's own research, and policy emphasis, is on the biological differences among individuals with varying risks of violent offending [3]. Some of the measures necessary for an effective comprehensive program will have to discriminate between these groups on the basis of biological markers. Certain measures-pharmacological, dietary, and behavioral-will be tailored to those identified as predisposed to violence, whether characterized as aggressive, vulnerable, or lacking in resilience. The parents of those individuals will have heightened duties of prevention and face closer surveillance by public health and safety officials. Such tailored measures may be justifiable on balance, but they raise serious issues about the stigmatization of children and the autonomy of their parents.

As Giodano et al. [9] note,

[i]n order to accurately depict any neurodevelopmental (pre-)dispositions... it would be important to obtain requisite data early and often-particularly if some intervention to divert aggressive or violent behavioral trajectories were to be initiated. This would necessitate... assessments throughout the lifespan and even, perhaps, prenatally so as to ascertain baseline findings.... Such a vision of statesponsored "dual -use" findings exposes a difficult paradox of seeking to improve accuracy by expanding available data while simultaneously grappling with the ethical ambiguities of consent/assent in minors and the possible future uses and abuses of obtained findings.

Horstkotter et al. [14] note the adverse effects likely to result from a focus on young children:

[D]espite potential benefits, biomedically informed means of early crime prevention could also have negative side-effects that challenge, in a variety of ways, the best interests of the children concerned.....Stigmatizing effects could arise, or children might learn to behave as the passive victims of their brains or genes.... [A]lso, parents and third parties could come to perceive identified children in a more negative way than they perhaps otherwise would have done.

Further parenting challenges would arise if violent behavior were not linked only to childhood maltreatment but also to stress, anxiety, and unintentional trauma. Caspi et al. [15] have found that certain genetic variants interact with adult stress and trauma to increase the probability of depression. It does not seem implausible that those genetic factors could have a similar interaction in childhood. It would be far more difficult for parents to protect their children from such factors than to refrain from abusing and neglecting them. Moreover, the former kinds of protection would involve difficult tradeoffs: in many childhood contexts, from academic honors programs to competitive sports, stress may be an unavoidable concomitant of challenge and enrichment. ${ }^{1}$

A distinct problem would confront parents and policy makers if the contribution of genetic variations to violent behavior were reversed in different environments, i.e., if an individual with variant $\mathrm{A}$ was more violent in one type of rearing environment than an individual with variant $\mathrm{B}$, but less violent in another. Julia Kim-Cohen and Andrea Gold [16], citing Belsky et al. [17], raise the possibility that "genetic variation confers differential susceptibility to environments for better and for worse. Tabery [18] argues that MAOA research reveals just such a crossover effect, or what he describes as an "interactive predisposition." He suggests that in families with warm, supportive nurturing, individuals with low MAOA variants may be less violenceprone than individuals with high MAOA variants. If both types of environments are common, it would make the identification of any particular variant less stigmatizing. But it would also complicate prediction and intervention. The earlier the intervention, the more effective it would likely be. For this reason, parents and physicians would

\footnotetext{
${ }^{1}$ The concern in this paragraph was raised by the Section Editor, Lisa Parker.
} 
have to predict what kind of environment the child would be reared in. But since parental treatment is the critical environmental variable, such prediction would require parents to assess their own future nurturing or subject them to questionable generalizations. Tabery describes an "interventionist's dilemma," where early intervention would risk having the reverse of the desired effect, while later intervention would likely be ineffective.

\section{Early Detection and Prevention: Role Conflicts for the Health Professional}

The ability to employ predisposition-specific interventions obviously depends upon the identification of predispositions in individuals. Some forms of pediatric screening may become routine as the cost of genomic testing declines, and its diagnostic and predictive value increases. But not all parents and pediatricians are likely to welcome such screening, which presents difficult issues about parental autonomy and clinician responsibility. Should pediatricians be required by professional associations, insurers, or the state to offer such screening, as they are now required to offer various somatic tests? Should parents not be allowed to opt out of such testing, or to decline to receive the results? If parents must be told of the results, should they be required to act on them? Could the failure to do so be considered a form of neglect? Should pediatricians be required to report "positive" findings to child welfare or public health authorities, even though any danger to third parties would be far from imminent? Should professional or public authorities be permitted to act on those findings, by requiring the child to receive specific treatment or close monitoring? These questions, which implicate serious ethical issues, have yet to be addressed. But social policy cannot pursue the goal of ensuring a minimal biological baseline of healthy brain development without answering them affirmatively.

Selective screening would raise familiar issues about discrimination and stigmatization. Families with histories of violent behavior are likely to have suffered various adverse social consequences, which may be exacerbated by selective behavioral screening. Selective screening may also miss families that "pass under the radar," as well as many children with predispositions arising from new mutations or perinatal and early environmental conditions. The articulation and implementation of criteria for selecting those to be screened could be subject to prejudice or abuse. Concerns about stigmatization would be mitigated if the screening were truly voluntary, but voluntary screening could miss a high proportion of predisposed children, given the incentives parents would have not to have their children labeled.
The alternative of universal screening would be equally problematic, however. Most states now impose mandatory or "opt-out" newborn screening for a list of conditions that expands with advances in diagnosis and treatment [19]. There is a continuing debate about the appropriate criteria for inclusion on such lists, and on whether specific conditions satisfy those criteria. But it is doubtful that tests for genetic predispositions to violence would satisfy most widely accepted criteria [20]. Although immediate intervention may be helpful, it is unlikely to be necessary. And it is highly unlikely that any intervention will approach the success rate of, for example, a phenylalanine-free diet for PKU. Moreover, the identification of predispositions would have significant costs. Because of the probabilistic character of biomarkers, there would be a high, if unascertainable rate of false positives-of children with those markers who would never display violent behavior whether or not they received special interventions. Even accurate identification of predispositions would have costs in parental overreaction and social exclusion. While these uncertainties and costs would not preclude the use of these tests for some newborns in some circumstances, they weigh heavily against universal or mandatory screening.

Moreover, both selective and universal screening would be problematic in the absence of parental consent or permission, which is considered not only ethically required, but also a first step in educating parents about the conditions for which the child is tested. Information about a predisposition to violence would be difficult to convey to most parents and burdensome to receive. Communicating that information adequately would require health professionals to explain the complexity of biological influences, their probabilistic character, and the critical role of the environment. Even if clinicians were trained to explain this, many parents, even well-educated ones, would find the information difficult to absorb and retain. If parents focused exclusively on the biological findings, they might become fatalistic about their child's prospects; if they focused on the social and environmental mediators, they might become overly anxious and overprotective. It would require unusual intellectual and emotional discipline for parents to steer a middle course between the two.

Implementation of predisposition screening would raise the issue of disclosure to third parties, in particular, state agencies. If parental consent were required for disclosure, it would likely be denied by many or most parents, reluctant to bring their young children to the attention of state authorities. If disclosure did not require parental consent, it would represent a far greater exception to confidentiality than any recognized thus far. Courts and legislatures of most American states have already imposed two exceptions to the health care professional's legally protected duty of confidentiality: imminent danger to third parties, and 
suspected child abuse or neglect $[11,21]$. These imposed duties create obvious conflicts for professionals, but these conflicts are less extensive and frequent than those likely to arise under legislation that would require (or even permit) clinicians to report violence-predisposition findings.

Information on behavioral predispositions will be more intrusive to obtain and of less immediate value than observations of neglect or abuse. Unlike abuse and neglect and threats to third parties, predispositions will often not be revealed by observation or history, but require testing. And unlike suspicions of abuse and neglect, or judgments of imminent danger, the threats to be averted are remote and uncertain. A reporting requirement for positive results would go well beyond the duty to warn or protect required by Tarasoff [22] and later cases. Even recent laws enacted in the wake of the Newtown shooting, mandate reporting only when the professional judges that the patient or client is "likely to engage in conduct that would result in serious harm to self or others" [23]. Moreover, such reporting merely results in measures to prevent the individual from acquiring or retaining firearms, measures less restrictive than civil commitment or forced treatment.

Another reporting requirement that provides some precedent for mandatory predisposition-reporting concerns conditions likely to impair patients' driving ability, such as seizure disorders and perceptual, motor, or cognitive impairment, often age related. Such requirements, imposed by several states and recommended by the American Medical Association, remain controversial [24]. But they are more clearly justified than a requirement to report predispositions to violence. Patients with driving-related impairments pose a significant, well-documented threat of physical harm to others in the near future. In contrast, even if biomarkers could reveal a predisposition to violent behavior, the increased risk of such behavior would not be imminent, but arising over a period of years or decades. Such a threat would also be extremely difficult to assess, given the social and environmental contingencies that mediate violent behavior.

Moreover, disclosure has a much stronger paternalistic justification for driving-related impairments than it would for predispositions to violence. Physician disclosure in the former case would protect the patient's health and safety at least as much as it protected the health and safety of others, given the high proportion of serious accidents that involve only the driver. Disclosure of violence predispositions would provide less, and less direct, health and safety protection for the child identified, even if effective interventions were available, while imposing burdens of stigma and social control.

The final issue concerns the parents' right to refuse preventive interventions on behalf of their minor children. As noted, behavior-affecting interventions would likely have to begin at an early age to be effective, or would be more effective the earlier they begin. But parents have long enjoyed considerable autonomy in deciding whether to accept or reject treatment on behalf of their children. Their refusal is overridden, as in the case of transfusions, when the treatment is necessary to prevent imminent death or serious and irreversible damage to their child. There are many close and difficult cases [25], but it would be difficult to justify an exception for even the most effective behavior-affecting interventions, let alone those with adverse social consequences and uncertain prospects of success.

\section{Conclusion}

I have raised several concerns about testing to reveal genetic predispositions to violence. My focus has been on the testing of children, and on the burdens that measures to detect and address those predispositions may place on parents and health professionals. Horstkoller et al. [26] have argued that most of these burdens are already imposed by social screening and interventions. As I suggested earlier, biological and social detection and intervention are likely to become more closely interwoven with the discovery of more, and more complex, gene-environment interactions. But the increasing attention paid to the child's environment as well as his biological endowment will not ease the conflicts facing health professionals, forced to balance their primary duty to their patients against the mounting pressures to detect potential threats to public safety.

Disclosure D. Wasserman declares no conflict of interest.

Human and Animal Rights and Informed Consent This article does not contain any studies with human or animal subjects performed by any of the authors.

\section{References}

1. Wasserman D. Research into genetics and crime: consensus and controversy. Polit Life Sci. 1996;15(1):107-9.

2. Kim-Cohen J, Caspi A, Taylor A, Williams B, Newcombe R, Craig IW, Moffitt TE. MAOA, maltreatment, and gene-environment Interaction predicting children's mental health: new evidence and a meta-analysis. Mol Psychiatry. 2006;11(10):903-13. doi:10.1038/sj.mp.4001851.

3. Glenn AL, Raine A. Neurocriminology: implications for the punishment, prediction and prevention of criminal behaviour. Nat Rev Neurosci. 2013;15(1):54-63.

4. Wood DB. US-crime-rate-at-lowest-point-in-decades.-WhyAmerica-is-safer-now The Wall Street Journal [Internet] 2012 January 9 [cited 2014 Jul 1]. http://www.csmonitor.com/USA/ Justice/2012/0109/. 
5. Pieri E, Levitt M. Risky individuals and the politics of genetic research into aggressiveness and violence. Bioethics. 2008;22(9):509-18.

6. Marshall E. A sinister plot or victim of politics? Science. 2000;289(5479):571.

7. Perry M. The neighborhood effect. The Chronicle Review (Chronicle of Higher Education) [internet] 2012 Nov 5. [cited 2014 Jun 27]. http://chronicle.com/article/The-NeighborhoodEffect/135492.

8. Schildkraut J, Muschert GW. Violent media, guns, and mental illness: the three ring circus of causal factors as related in media discourse. In: Agger B, Luke TW, editors. Gun violence and public life. St. Paul: Paradigm Publishing; 2013.

9. Giordano J, Kulkarni A, Farwell J. Deliver us from evil? The temptation, realities, and neuroethico-legal issues of employing assessment neurotechnologies in public safety initiatives. Theor Med Bioeth. 2014;35(1):73-89.

10. Hall RCW, Friedman H. Guns, schools, and mental illness: potential concerns for physicians and mental health professionals. Mayo Clin Proc. 2013;88(11):1272-83.

11. Swanson J. Mental illness and new gun law reforms: the promise and peril of crisis-driven policy. JAMA. 2013;309(12):1233-4.

12. Berger G. Chilling look at newtown killer, but no 'why', The New York Times [Internet] 2013 November 25 (cited 2014 Jun 26). http://www.nytimes.com/2013/11/26/nyregion/sandy-hookshooting-investigation-ends-with-motive-still-unknown.html?page wanted=all\&_r=0.

13. Raine, R. Opinion: Unlocking crime using biological keys, CNN [internet]. 2014 April 15 (cited 2014 Apr 17). http://www.cnn. com/2013/05/03/health/biology-crime-violence/index.html.

14. Horstkötter D, Berghmans R, de Wert G. Moral enhancement for antisocial behavior? An uneasy relationship. AJOB Neurosci. 2012;3(4):26-28, 27.

15. Caspi A, Sugden K, Moffitt TE, Taylor A, Craig IW, Harrington $\mathrm{H}$, Poulton R. Influence of life stress on depression: moderation by a polymorphism in the 5-HTT gene. Science. 2003;301(5631):386-9.

16. Kim-Cohen J, Gold AL. Measures gene-environment interaction and mechanisms promoting genetic development. Curr Dir Psychol Sci. 2009;18(3):138-42.

17. Belsky J, Bakermanns-Kranenburg MJ, van IJzendoorn MH. For better and for worse: differential susceptibility to environmental influences. Curr Dir Psychol Sci. 2007;16:300-304

18. Tabery J. From a genetic to an interactive predisposition: rethinking the ethical implications of screening for gene-environment interactions. J Med Philos. 2009;34:27-48.

19. Baily MA, Murray TH. Ethics, evidence, and cost in newborn screening, The Hastings Center Report 2008 May/Jun; 38(3): 23-31.

20. Fleishman AR, Lin BK. Howse JL A commentary on the president's council on bioethics report: the changing moral focus of newborn screening. Genet Med. 2009;11(7):507-9.

21. Freckelton I. Privacy and confidentiality: the doctor's obligations. In: Beran RG, editor. Legal and forensic medicine. Berlin: Springer Publishing; 2013, p. 1683-97. http://link.springer.com/ referenceworkentry/10.1007/978-3-642-32338-6_147.

22. Tarasoff v. Regents of the University of California. California Reporter. $1973 ; 108$, p. 878.

23. Dugan LZ. Reporting requirements and the New York SAFE Act of 2013, University of Pittsburgh ETD [Internet]. 2014 January 27, 2014 (cit9ed 2014 Apr 20). http://d-scholarship.pitt.edu/ 20224/.

24. Berger JT, Rosner F, Kark P, Bennett AJ. Reporting by physicians of impaired drivers and potentially impaired drivers. J Gen Intern Med. 2000;15(9):667-72.

25. Wadlington W. Medical decision making for and by children: tensions between parent, state, and child. University of Illinois Law Review 1994 (1994):311-336.

26. Horstkotter D, Berghmans R, de Wert G. Early prevention of ASB: a comparative ethical analysis. BioSocieties. 2014;9(1): $60-83$. 